\title{
RESOLUÇÃO 510/2016: REFLEXÕES DESDE A INSERÇãO EM UM COMITÊ DE ÉTICA EM PESQUISA
}

\author{
DEISE JULIANA FRANCISCO ${ }^{1}$ \\ LUCIANA SANTANA ${ }^{2}$
}

\begin{abstract}
RESUMO
Este artigo discute alguns aspectos da Resolução 510/2016 à luz da implicação da autora como membro de Comitê de Ética em Pesquisa. Apresenta reflexões sobre temas tais como consentimento livre e esclarecido e vulnerabilidade, problematizando a questão do anonimato do participante em alguns tipos de pesquisa. Conclui que a Resolução 510/2016 apresenta algumas especificidades das pesquisas no campo das Ciências Humanas e Sociais, contribuindo com a avaliação ética das pesquisas e ao respeito à diversidade metodológica das pesquisas, apesar de ainda não concretizar uma efetiva ruptura com a regulação e avaliação ética em pesquisa no Brasil.
\end{abstract}

\section{PALAVRAS-CHAVE}

Resolução 510/2016; Vulnerabilidade; Comitê de Ética em Pesquisa

\author{
RESOLUTION 510/216: \\ REFLECTIONS FROM INSIDE A RESEARCH ETHICS COMMITTEE
}

\begin{abstract}
This article is a summary of Resolution 510/2016 in light of the author's implication as a member of the Research Ethics Committee. It presents reflections on topics such as free and informed consent and vulnerability, problematizing the question of the participant's anonymity in some types of research. It concludes that Resolution 510/2016 on the subject of Human and Social Sciences, which contributes to an ethical evaluation of the researches and a respect for the methodological diversity of the research, although it does not materialize an effective rupture with an evaluation and ethical evaluation in research in Brazil.
\end{abstract}

\section{KEYWORDS \\ Resolution 510/2016; Vulnerability; Research Ethics Committee}

\footnotetext{
${ }^{1}$ Psicóloga, licenciada em psicóloga, doutora em informática na educação, professora do Cedu/Ufal. É membro do Programa de Pós Graduação em Educação (PPGE-UFAL), do Programa de Pós Graduação em Ciência, Tecnologias e Instituições (PPGCTI-UFERSA) e do comitê de ética em pesquisa da UFAL.

2 Professora adjunta de Ciência política no Instituto de Ciências Sociais da UFAL. Graduada em História, é Mestre e Doutora em Ciência Política pelo DCP/UFMG, com instância sanduíche na Universidade de Salamanca. É membro do Comitê de ética em Pesquisa da UFAL desde 2011 e ocupa, atualmente, a função de coordenadora.
} 


\title{
RÉSOLUTION 510/2016: \\ RÉFLEXIONSÀ PARTIR DE L'INSERTION DANS UN COMITÉ D'ÉTHIQUE EN RECHERCHE
}

\begin{abstract}
RÉSUMÉ
Cet article a par but mettre en lumière la Résolution 510/2016 à partir du point de vue de l'implication de l'auteur en tant que membre du Comité d'éthique en recherche. Il présente des réflexions sur des questions comme le consentement éclairé et de la vulnérabilité et la question de l'anonymat des participants dans certains types de recherche. On conclut que la Résolution 510/2016, en ce qui concerne la question des sciences humaines et sociales, contribue à une évaluation éthique de la recherche et de respecter la diversité de la recherche méthodologique. Il ne s'agit pas de terminer une rupture efficace avec une éthique d'évaluation et d'évaluation de la recherche au Brésil.
\end{abstract}

\section{MOTS-CLÉS}

Résolution 510/2016; La vulnérabilité; Comité d'éthique de la recherche

\section{RESOLUCIÓN 510/2016: \\ REFLEXIONES DESDE LA INSERCIÓN EN UN COMITÉ DE ÉTICA EN INVESTIGACIÓN}

\section{RESUMEN}

Este artículo es un resumen de la Resolución 510/2016 a la luz de la implicación de la autora como miembro del Comité de Ética en Investigación. Presenta reflexiones sobre temas como el consentimiento libre y esclarecido y la vulnerabilidad, problematizando la cuestión del anonimato del participante en algunos tipos de investigación. Concluye que la Resolución 510/2016 referente al tema Ciencias Humanas y Social, que contribuye con una evaluación ética de las investigaciones y un respeto a la diversidad metodológica de las investigaciones, a pesar de no concretar una efectiva ruptura con una evaluación y evaluación ética En investigación en Brasil.

\section{PALABRAS CLAVE}

Resolución 510/2016; Vulnerabilidad; Comité de Ética en Investigación 


\section{INTRODUÇÃO}

O cotidiano de um Comitê de Ética em pesquisa (CEP) é eivado de discussões e de aprendizagens, em que diferentes pesquisadores, professores, representantes dos usuários problematizam seus fazeres e pensares a partir de protocolos de pesquisa específicos. De tais discussões, emerge um parecer coletivo que deve ser avaliado pelo (a) coordenador (a) do colegiado. A depender da composição de cada CEP, a discussão pode gerar discussões, estudos, trabalhos a serem apresentados em congressos e livros. Neste sentido, as resoluções sobre ética em pesquisa servem como guias, em que se encontram as linhas mestras de avaliação e de acompanhamento ético das pesquisas.

Pesquisas realizadas sobre o cotidiano de CEP nacionais apontam que há predomínio de coordenadores com formação nas áreas de Ciências Biológicas e da Saúde, sendo pesquisadores em exercício, com formação de mestrado e doutorado e faixa etária entre 40 e 60 anos. Porém, quanto à composição dos membros, encontrou-se maior diversidade:

Considerando todos os membros dos CEP, a formação acadêmica é diversificada: em 369 respostas, 92 membros (25\%) são da área de ciências biológicas e da saúde, 82 (22\%) são da área de ciências humanas, 73 (20\%) são da área de ciências sociais, 66 (18\%) das ciências exatas e 56 sem formação acadêmica (15\%) (JÁCOME; ARAUJO; GARRAFA, 2017, p. 64).

Neste sentido, a avaliação ética tende a contemplar a especificidade das áreas, mostrando um quadro diferente do encontrado anteriormente quanto à composição dos membros dos CEP.

As diretrizes da avaliação dos protocolos de pesquisa seguem as resoluções e materiais de capacitação disponibilizados pela Comisão Nacional de Ética em Pesquisa $(\mathrm{CONEP})^{3}$, ao mesmo tempo em que há propagação maior de cursos de formação em ética em pesquisa e bioética. Este contexto é relevante e pode construir uma cultura de discussão ética que subsidie a formação tanto de membros de CEP quanto da comunidade acadêmica em geral.

\footnotetext{
${ }^{3}$ A Comissão Nacional de Ética em Pesquisa (CONEP) está diretamente ligada ao Conselho Nacional de Saúde (CNS). Ela foi criada pela Resolução do CNS 196/96 como uma instância colegiada, de natureza consultiva, educativa e formuladora de diretrizes e estratégias no âmbito do Conselho. Além disso, é independente de influências corporativas e institucionais. Uma das suas características é a composição multi e transdiciplinar, contando com um representante dos usuários. A CONEP tem como principal atribuição o exame dos aspectos éticos das pesquisas que envolvem seres humanos. Como missão, elabora e atualiza as diretrizes e normas para a proteção dos sujeitos de pesquisa e coordena a rede de Comitês de Ética em Pesquisa das instituições. Cabe a CONEP avaliar e acompanhar os protocolos de pesquisa em áreas temáticas especiais com o: genética e reprodução humana; novos equipamentos; dispositivos para a saúde; novos procedimentos ; população indígena; projetos ligados à biossegurança e como participação estrangeira. A CONEP também se constitui em instância de recursos para qualquer das áreas envolvidas" (http://conselho.saude.gov.br/web_comissoes/conep/).
} 
Neste sentido, lembra-se que o trabalho nos CEP não se restringe ao preenchimento de check list dos protocolos baseado no modelo de avaliação ética constante nas resoluções, mas revela-se como uma mostra da representação de ética de cada membro bem como da marcação da formação específica do campo de saber. Em termos de Resoluções, estas demarcam também um território de significados. Neste sentido, há uma discussão importante sobre a manutenção do principialismo nas atuais resoluções de ética em pesquisa no Brasil.

A ética principialista tem recebido críticas, por ser universal e, neste sentido, não acatar as diferenças culturais. Diniz e Guilhem (2008) enfatizam a crítica, ao sublinhar que os quatro princípios (autonomia, beneficência, não maleficência e justiça) não chegam a tocar a realidade de muitos participantes da pesquisa e podem, até mesmo, encobrir as diferenças sociais sob o manto da cientificidade e da ética em pesquisa. O princípio da autonomia, por exemplo, pressupõe que os sujeitos sejam livres e autônomos para tomar decisões conscientemente, livres de condicionantes sociais. Mas, em países periféricos e em desenvolvimento podemos pensar em sujeitos, grupos em que os condicionantes não passam a subjetivar os cidadãos? No outro lado deste princípio, está o conceito de vulnerabilidade, no qual alguns sujeitos e ou grupos teriam sua integridade protegida, na medida em que não podem exercer sua autonomia, pelo menos em termos gerais. Pensa-se aqui nas populações indígenas, pessoas em sofrimento psíquico, crianças e outros: "Dessa questão emerge, ainda, a tênue fronteira entre a autoridade sobre essas pessoas e a proteção delas, que poderia justificar, por exemplo, o silenciamento (Diniz \& Guilhem 2008)" (SILVA; PEREIRA, 2016, p. 123).

No mesmo caminho, Jácome, Araujo e Garrafa (2017) lamentam que a Declaração Universal sobre Bioética e Direitos Humanos (DUBDH) da Unesco não tenha sido incorporada à Resolução 466/12 "como fundamento epistemológico da Resolução proporcionaria significativa ampliação de seu campo de ação. Isso porque passaria a incorporar também áreas não abarcadas pela limitada corrente principialista antes referida" (p. 66). Isso porque a análise ética dos protocolos e acompanhamento das pesquisas pelos CEP em contextos de desigualdade marcantes na população careceria de referenciais mais plurais e contextuais. Neste sentido, lembramos da bioética de intervenção e da bioética de proteção. Oriundas do contexto latino-americano, estas apresentam que devemos tomar decisões a partir do desenvolvimento biotecnológico e perante questões já clássicas no campo da bioética (aborto, eutanásia, etc.), adotando "o princípio do consequencialismo solidário na esfera pública, legitimizando a responsabilidade do Estado no provimento do bem estar da população" (FELICIO; PESSINI, 2009, p. 217) e, ainda, especificamente na Bioética de Proteção defende-se, "a gratuidade, ao não se supor um compromisso prévio às ações de proteção; de vinculação, que aponta que tendo havido a necessidade de proteção, esta se 
torna um dever; e de segurança efetiva das necessidades do cidadão vulnerável que eliciou o dever de proteção positiva" (idem).

A Resolução 466/12 cita a Constituição Federal do Brasil como norma máxima e outras leis. Na conceituação de participante da pesquisa, a mesma traz elementos presentes no Código de Defesa do Consumidor, Código Civil Brasileiro, ao Estatuto da Criança e do Adolescente, ao Estatuto do Idoso:

O Código de Defesa do Consumidor (CDC) traz uma contribuição importantíssima na proteção dos indivíduos e dos grupos que são submetidos às pesquisas de qualquer área do conhecimento, inclusive linguística, com a noção de vulnerabilidade. Pode até nos causar certo estranhamento a utilização do CDC às pesquisas que não se configuram relações de consumo; o fato é que o CDC apenas empresta a noção de vulnerabilidade para ser aplicada às relações entre as instituições, pesquisadores e os sujeitos pesquisados. Essa noção de vulnerabilidade também está fortemente presente no Estatutoda Criança e do Adolescente e no Estatuto do Idoso, que colocam a criança, o adolescente e o idoso como naturalmente vulneráveis. No caso da Resolução n.466/12, a vulnerabilidade é característica intrínseca dos sujeitos participantes da pesquisa (ABREU, 2016, p. 12).

Este ponto é interessante, pois adentramos o que se entende por participante da pesquisa e de sua relação desigual entre pesquisadores e participantes.

Luís Roberto Cardoso de Oliveira (2004) discute sobre a diferença de entendimento sobre a relação instituída (ou a instituir-se) entre quem pesquisa e quem participa da pesquisa ou é pesquisado e que esta é dada pelos campos disciplinares. Neste sentido, o autor aponta que há pesquisas em seres e pesquisa com seres humanos. No primeiro caso, teríamos pesquisas do campo biomédico, nos quais os participantes seriam pesquisados quanto à sua saúde, condições de vida e outros elementos. No segundo caso, nas pesquisas das Ciências Humanas e Sociais, os participantes teriam um lugar privilegiado, de interlocutor da pesquisa, Nestas, os seres humanos (tanto participantes quanto pesquisadores) construiriam a pesquisa conjuntamente. Tratar-se-ia de uma diferença semântica? Não apenas, mas sim uma diferença epistemológica. Esta diferença epistemológica se manifesta não apenas no campo teórico, mas também nas relações com agências de fomento e na regulamentação ética em pesquisa, numa intrincada rede de saber-poder. Nas palavras de Freitag (s/d):

[...] não temos um código de ética de pesquisadores. Esta questão tem trazido à tona discussões no meio acadêmico, especialmente movidas pelas regulamentações da CNS e pelas agências de fomento à pesquisa - para uma discussão mais detalhada, a leitura dos trabalhos de Rocha et al. (2012), Russo (2014), Spink (2014), Villaça (2015), dentre outras produções recentes no campo, é esclarecedora. Os órgãos de fomento à pesquisa, pressionados pelo crescente processo de judicialização questionando as práticas, têm desenvolvido seus instrumentos, como o Código de Boas Práticas de Pesquisa da FAPESP e o relatório da Comissão de Integridade em Atividades de Pesquisa, do CNPq. O Código de Boas Práticas da FAPESP, por exemplo, orienta quanto à concepção, proposição e realização da pesquisa (originalidade e relevância); à comunicação dos resultados (plágio, autoria, salami science); ao registro, conservação e acessibilidade dos dados; à avaliação pelos pares; ao conflito potencial de interesses; e à responsabilidade das tutorias (s/p). 


\section{RESOLUÇÃO 510/2016}

O Brasil tem se preocupado em traçar algumas diretrizes sobre ética em pesquisa desde 1988, quando foi promulgada a primeira resolução nacional. Passados alguns anos, foi discutida e proposta a Resolução 196/96, que ficou em ação e permitiu o fortalecimento do sistema CEP/CONEP. Durante sua aplicação, muitas discussões advindas de pesquisadores que trabalhavam com pesquisa qualitativa foram tomando vulto, tendo em vista sua não compatibilidade com termos, critérios de avaliação, sistemática da pesquisa, sendo muitos protocolos não aprovados devido à diferença de modelo de pesquisa que apoiava a análise ética pelos CEP. Tal movimento foi se intensificando e a Resolução 466/12 não contemplou a pesquisa qualitativa em sua especificidade. Da mesma forma, não houve mudanças drásticas entre a Resolução 196/96 e a 466/12:

Atualmente, as diretrizes éticas nacionais para pesquisas envolvendo seres humanos estão definidas na Resolução 466/2012 do Conselho Nacional de Saúde (CNS). Homologada pelo Ministério da Saúde em 13 de junho de 2013, substitui a Resolução CNS 196/1996, que vigorou por quase 17 anos. Embora a resolução mais recente não tenha introduzido mudanças de grande magnitude em relação ao texto anterior, no tocante ao processo de avaliação e operacionalização dos CEP incluiu modificações que podem propiciar avaliações éticas mais pertinentes aos diferentes delineamentos das pesquisas.

Entre as mudanças que não geraram controvérsias, destacam-se: definição e concepção de pesquisa não restritas à obtenção de conhecimento generalizável, formulação de hipóteses e estudos amostrais; possibilidade de se obter o termo de consentimento livre e esclarecido (TCLE) a posteriori (desde que necessário e comprovadamente justificado). Além disso, apresenta normas atinentes às pesquisas nas áreas das ciências da saúde em itens e subitens específicos e criação de resolução complementar com diretrizes e normas voltadas às particularidades das pesquisas em ciências humanas e sociais (JÁCOME; ARAUJO; GARRAFA, 2017, p. 62).

Em termos de operacionalização e de transparência das pesquisas nacionais, foi criada a Plataforma Brasil, que é uma base de dados digital, disponível na Internet "nacional e unificada de registros de pesquisas envolvendo seres humanos para todo o sistema CEP/Conep [...] propiciando ainda à sociedade o acesso aos dados públicos de todas as pesquisas aprovadas" (http://aplicacao.saude.gov.br/plataformabrasil/login.jsf; jsessionid=0206B1740F4F08E1613378AEF0E47B44.server-plataformabrasil-srvjpdf131). modelo de projeto inserido na plataforma tece algumas adaptações para as pesquisas qualitativas, em questões tais como hipótese da pesquisa, critério de inclusão e exclusão da amostra (na qual o pesquisador pode optar por "não se aplica"). Apesar disso, todos os protocolos de pesquisa devem ser submetidos à Plataforma para apreciação do sistema CEP/CONEP.

Como fruto da ação articulada de pesquisadores das Ciências Humanas e Sociais e suas associações, um grupo de trabalho teve início e propôs o que viria a ser uma minuta da 
Resolução 510/2016. Isso pelo embate entre a normativa baseada no saber biomédico e a atuação dos pesquisadores do campo das Ciências Humanas e Sociais:

Tal situação produziu um choque entre duas culturas de pesquisa distintas e, portanto, duas concepções bastante diferentes sobre o que podem ser considerados problemas éticos e como lidar com eles. De um lado dessa disputa colocou-se o modelo das ciências biomédicas, que segue uma tradição de proteção de direitos e bem-estar dos sujeitos de pesquisa baseada na codificação das práticas e no controle externo das atividades de pesquisa, o padrão adotado pelo CNS. Do outro lado, encontramos o modelo das ciências humanas, ciências sociais e ciências sociais aplicadas (CHS), no qual uma maior ênfase é colocada em aspectos políticos e relacionais do processo de pesquisa (Guerriero \& Dallari, 2008), que está muito menos sujeito, portanto, à codificação (Hoeyer; Dahlager; Lynöe, 2005) e, consequentemente, ao controle externo. A regulação desse tipo de abordagem tradicionalmente se dá pela via de códigos que estabelecem princípios gerais que devem ser interpretados pelo pesquisador vis-à-vis cada situação encontrada, significando uma maior responsabilidade do pesquisador individual no controle ético da atividade de pesquisa (PEIXOTO, 2016, p. 325).

A Resolução 510/16 foi aprovada no dia 7 de abril de 2016 do Conselho Nacional de Saúde, do Ministério da Saúde, como resolução complementar à Resolução 466/2012 e entrou em vigor no dia 24 de maio do mesmo ano. Apesar de ser complementar, a resolução traz princípios e conceitos já presentes na 466/12, na tentativa de elucidar seu campo específico. À exemplo disso, temos a delimitação do que deve ou não passar pelo sistema CEP/CONEP em que constam pesquisas bibliográfica. Ora, isso já estava presente desde as primeiras resoluções, quando se delimitava o foco a pesquisas que envolvam direta ou indiretamente seres humanos. Obviamente, a questão que se coloca aqui é o que se entende como ser humano, a relação entre seres humanos e a produção do conhecimento científico. Amaral Filho discute estas questões, ponderando que:

Então, o que se passa com a regulamentação ética na pesquisa científica no Brasil se reduz única e exclusivamente a uma questão de poder? Ao que parece, quando adentramos nas discussões que a permeiam, sim - o que, para nós, tratando-se da ciência, poder-se-ia dizer, é quase que natural. Ainda que saibamos que tal suposta natureza seja uma grande ilusão, ou, ainda, parte de uma determinada ideologia. É fato, desde Platão sabemos "[...] que um grande poder e a ciência tendem a se unir, pois incessantemente se procuram entre si, se perseguem e se encontram" (PLATÃO, 1992, 310e). E, além do mais, em se tratando das questões da ética, não podemos esquecer que, ao fim e ao cabo, é sempre a questão política, e, portanto, a questão do poder que está em jogo. Desde Aristóteles, a ética sempre tem sido associada à política, da qual, para o estagirita, é um saber subsidiário, um não se constituindo sem o outro. Portanto, ainda hoje, "[...] não há como fugir dessa qualidade elementar da ética, qual seja, seu conteúdo político" (FIGUEIREDO, 2004, p. 113). Assim sendo, não há como negar, principalmente se atentarmos para as contradições internas ao tema que historicamente vem delimitando-o, que "[...] a discussão sobre ética em pesquisa e sua regulamentação é, portanto, uma discussão política" (GUERRIERO; MINAYO, 2013, p. 764). Sendo uma questão fundamentalmente política, cabe a nós das CHS lutar contra aquilo que, em relação à revisão ética na pesquisa científica, está sendo chamado de imperialismo bioético, em que as CHS estão sendo tratadas "como áreas de colonização" (DUARTE, 2015, p. 42) pelo saber biomédico, forçando-nos a seguir seus parâmetros, tão contrários ao nosso próprio saber (AMARAL FILHO, 2017, p. 259). 
Assim, a Resolução 510/16 tem como foco as pesquisas qualitativas e não todo o tipo de desenho metodológico de pesquisa que se realiza no âmbito das Ciências Humanas e Sociais. À todo momento são apresentadas as especificidades do campo, apesar delas não serem explicitadas claramente ao longo da resolução. Isso se faz presente logo no preâmbulo da Resolução 510/16:

Considerando que as Ciências Humanas e Sociais têm especificidades nas suas concepções e práticas de pesquisa, na medida em que nelas prevalece uma acepção pluralista de ciência da qual decorre a adoção de múltiplas perspectivas teóricometodológicas, bem como lidam com atribuições de significado, práticas e representações, sem intervenção direta no corpo humano, com natureza e grau de risco específico.

Interessante notar que o corpo humano é retirado do campo das Ciências Humanas e Sociais, afirmando-se que o mesmo se faz presente desde que não haja intervenção direta. Parece que no embate entre ciências biomédicas e humanas e sociais, a velha dicotomia entre corpo e mente se faz presente de forma enfática. Por outro lado, o grau de risco também consta como diferenciado das ciências biomédicas.

No capítulo I, dos termos e definições, da Resolução 510/16, há delimitação do campo das Ciências Humanas e Sociais como sendo:

XVI - pesquisa em ciências humanas e sociais: aquelas que se voltam para o conhecimento, compreensão das condições, existência, vivência e saberes das pessoas e dos grupos, em suas relações sociais, institucionais, seus valores culturais, suas ordenações históricas e políticas e suas formas de subjetividade e comunicação, de forma direta ou indireta, incluindo as modalidades de pesquisa que envolvam intervenção.

No tocante à submissão dos protocolos de pesquisa, ainda há a necessidade de encaminhamento via Plataforma Brasil, porém, a mesma deverá ser alterada, para aceitar o envio ou não do protocolo para análise completa pelo sistema, a depender da gradação de riscos (a ser regulamentada em outra resolução). Na Resolução 510/16, a gradação de risco é citada, mas a mesma será ainda regulamentada. Disso depende, também, a reformulação da Plataforma Brasil para atender especificidades e alteração do fluxo dos protocolos no sistema CEP/CONEP. E o que seria a gradação de riscos? O artigo 18 esclarece tal ponto:

Art. 18. Nos projetos de pesquisa em Ciências Humanas e Sociais, a definição e a gradação do risco resultam da apreciação dos seus procedimentos metodológicos e do seu potencial de causar danos maiores ao participante do que os existentes na vida cotidiana, em consonância com o caráter processual e dialogal dessas pesquisas.

Em outras sessões, entretanto, há uma definição e uma diferenciação mais propositiva quanto à especificidade do campo das Ciências Humanas e Sociais, quando, no artigo $3^{\circ}$ há referência à situação de vulnerabilidade. Assim, no artigo $3^{\circ}$ há a proposição de incentivo à participação de indivíduos ou grupos vulneráveis na pesquisa, diferentemente do assinalado nas outras resoluções anteriores a ela, quando se propunha proteção aos vulneráveis. 
Art. $3^{\circ}$ São princípios éticos das pesquisas em Ciências Humanas e Sociais: V - recusa de todas as formas de preconceito, incentivando o respeito à diversidade, à participação de indivíduos e grupos vulneráveis e discriminados e às diferenças dos processos de pesquisa.

A Resolução adota uma concepção de vulnerabilidade como não-universal, cultural e situada historicamente, incluindo tal grupo na pesquisa, como forma também de lutar contra a discriminação. Neste sentido, atenta para questões de gênero, sexualidade, etnia, classe social. A pergunta que fica é sobre a relação dos participantes da pesquisa com o pesquisador, no tocante à tutela. Em situações de vulnerabilidade, pode haver tutela e não proteção. Exercício de poder autoritário e não compartilhamento de saberes:

Portanto, a tutela pode ter o efeito perverso de silenciar indivíduos e coletividades e, como já alertado, em nome de uma suposta proteção, exercer autoridade sobre essas populações e impedir o conhecimento dessas realidades e, no caso de pesquisas engajadas, o aprimoramento e/ou a implementação de políticas voltadas a elas (SILVA; PEREIRA, 2016, p. 130).

Aqui o artigo 9 da resolução traz uma diferença que pode trazer inflexão na vida dos participantes das pesquisa, quando apresenta a possibilidade de identificacao dos participantes, desde que ele aprove. A saber: "Art $9^{\circ}$ Direitos dos participantes: $\vee$-decidir se sua identidade será divulgada e quais são, dentre as informações que forneceu, as que podem ser tratadas de forma pública".

Revelar ou não a identidade dos participantes da pesquisa? Рara iniciar esta discussão, trago dois excertos de pesquisas em que a não identificação dos participantes foi problematizada:

A pesquisa na era tecnológica causa alguns assombramentos: de um lado a perspectiva de procedimentos éticos em pesquisa, a partir dos quais a identidade dos participantes não pode ser declarada, tendo em vista possíveis desdobramentos em sua vida cotidiana e subjetividade e, por outro, a solicitação de reconhecimento da produção e da existência dos participantes realizada via recursos eletrônicos. Na perspectiva de uma direção dos procedimentos éticos, o que contaria seriam não nomes dos sujeitos da pesquisa, mas sim uma análise dos dados na qual a assepsia do nome fosse realizada. Porém, se a intervenção propiciou um espaço-tempo de autoria, como seguir os preceitos éticos de sigilo da identidade? Desta tensão, a opção foi a de manter os apelidos tal como utilizados na oficina, na tentativa de visibilizar a autoria, gritar que o processo é de sujeitos encarnados, vivos, medicados, algumas vezes em pleno processo de contenção química, viventes de uma comunidade e usuários de um serviço de saúde mental!

O nome dos sujeitos não é disponibilizado, devido ao fato de que estas questões foram trazidas com mais força após o encaminhamento do projeto ao Comitê de Ética e à assinatura do termo de compromisso livre e esclarecido. O texto acadêmico propõe uma escrita sem identificação do outro, mas o projeto de extensão, a pesquisa intervenção possibilitou um lugar de enunciação e de reconhecimento do sujeito. Este é apenas um dos movimentos que tive que realizar para escrever esta tese. Como falar de alguém que exige reconhecimento sem identificá-lo? Ainda mais em uma situação em que os dados estão disponibilizados na Internet! (FRANCISCO, 2008, p. 20-21).

Nesta primeira, o desenho da pesquisa intervenção e a pesquisa em ambientes digitais dirigem a ação para a explicitação de quem fala e desde onde fala. O processo de avaliação ética, ao não levar em consideração o desenho da pesquisa e a intenção de 
promover autoria perante ambientes digitais, pode contrariar todo o processo construído em diálogo com os participantes. Ao mesmo tempo, ao trabalhar com excertos da Internet, em que são apresentados os links, não tratar dos nomes dos participantes acaba por manifestar uma incongruência, na medida em que, na Internet constam os nomes e no relatório da pesquisa não.

Outro exemplo, inserido na pesquisa qualitativa, é oriundo de uma pesquisa no sistema do manicômio judiciário brasileiro, em que o nome da participante pode ser explicitado. Debora Diniz, inclusive cunhou uma expressão afirmando que "nomear é proteger", contrapondo-se à noção de que nomear levaria necessariamente à exposição do participante e sua vulnerabilidade:

Esta é uma pesquisa em arquivo sobre caso único. Zefinha só pode ser ela mesma -a mulher há mais tempo internada em um manicômio judiciário no país. Escrever a seu respeito nos moveu a defender a tese de que "nomear é proteger" (Diniz, 2015): anonimizá-la ou acobertar os registros geográficos e históricos que permitissem sua localização poderia amplificar o já amplo regime de precarização da vida a que foi submetida. Conhecemos Zefinha em 2010, quando visitamos as 26 unidades psiquiátrico-penais que abrigam loucos infratores no país. De cada hospital, recuperamos o dossiê do paciente mais antigo. Zefinha vive no Centro Psiquiátrico Judiciário Pedro Marinho, em Alagoas, e é a única mulher no grupo dos mais antigos do país. O homem mais antigo está internado há 46 anos em um manicômio judiciário no Nordeste do Brasil. O dossiê não é o prontuário médico, mas uma escrita entre os poderes policiais, judiciais e biomédicos. Não são documentos sigilosos. O guardião do dossiê é o diretor do hospital (DINIZ; BRITO, 2016, p.114-115).

Além destes exemplos, temos a discussão presente nas pesquisas com crianças, quando algumas chegam a deslegitimar a pesquisa quando sabem que seus nomes não aparecerão nas produções. O contrato, sempre feito e retomado traz em sua visceralidade a relação que se constrói de forma dialogada ao longo da pesquisa.

Conforme a Resolução 466/12, o sentido de confidencialidade e privacidade são elementos necessários para que uma pesquisa seja considera ética. Isso pode ser mantido e interessante em certos desenhos metodológicos tais como na pesquisa quantitativa ou em pesquisas sociais em que a não nomeação pode realmete proteger o participante nos seus direitos fundamentais (em pesquisas com tutores de educação a distância, quando eles fazem avaliação do sistema de trabalho, por exemplo. Sua não identificação pode preservar o trabalho). Porém, em outros casos, isso não ocorre e torna-se necessário problematizar tais práticas. Nas palavras de Debora Diniz (2015),

Arrisco, portanto, anunciar dois falsos pressupostos no dever da confidencialidade pela anonimização de Zefinha: o de que nomeá-la the causaria dano e o de que identificá-la violaria sua intimidade. O anonimato sobre a mulher abandonada há mais tempo em um manicômio judiciário no Brasil não protegeria aquela que vive esquecida, mas os poderes que permitiram sua existência (p. 2672).

Assim, o uso indevido da identificação levaria a invisibilizar Zefinha no sistema manicomial novamente, retirando da pesquisa seu tom político e, nesta medida, ético. A Resolução 510/16 abre a possibilidade para que a identidade seja explicitada. 
A questão do processo de consentimento livre e esclarecido foi outro ponto polêmico entre a perspectiva biomédica e das ciências humanas e sociais contemplado na Resolução complementar à 466/12. Ali se reforça o caráter processual do consentimento e se viabiliza a obtenção do mesmo por outras formas, retirando o caráter fortemente jurídico que havia na resolução 196/96. Tal abertura reforça o posicionamento sobre a relação que é construída entre pesquisador e participante da pesquisa, aspecto tão caro às pesquisas qualitativas. Pode-se verificar isso em duas passagens, nos artigos 5 e 16 :

Art. $5^{\circ} \mathrm{O}$ processo de comunicação do consentimento e do assentimento livre e esclarecido pode ser realizado por meio de sua expressão oral, escrita, língua de sinais ou de outras formas que se mostrem adequadas, devendo ser consideradas as características individuais, sociais, econômicas e culturais da pessoa ou grupo de pessoas participante da pesquisa e as abordagens metodológicas aplicadas.

Art.16. $\$ 1^{\circ}$ Os casos em que seja inviável o Registro de Consentimento ou do Assentimento Livre e Esclarecido ou em que este registro signifique riscos substanciais à privacidade e confidencialidade dos dados do participante ou aos vínculos de confiança entre pesquisador e pesquisado, a dispensa deve ser justificada pelo pesquisador responsável ao sistema CEP/CONEP.

O artigo 16 abre a possibilidade para discussão nos CEP e fica na dependência da formação dos membros do CEP e do diálogo entre pesquisadores e o coletivo do comitê. Isso porque cada CEP, em sua autonomia, vai construindo um cotidiano de decisões baseadas nas resoluções, que deriva da própria cultura local, da formação dos membros e mesmo do diálogo que se instaura. Ao mesmo tempo, o trabalho nos CEP depende da documentação apresentada e da intenção do pesquisador que se manifesta no protocolo de pesquisa. A questão sobre a eticidade é dado via protocolo e não, necessariamente, via a prática do pesquisador no campo de pesquisa. É claro que consta que uma das tarefas dos CEP é acompanhar as pesquisas, mas são poucos os que se dedicam a esta tarefa, tendo em vista disponibilidade de tempo, de recursos para os comitês. Lembremos que os membros de CEP são voluntários e nem sempre recebem contrapartida pelo horário reservado tanto para análise dos protocolos quanto para participação em capacitações e em plenárias. Assim, o mundo vivo da pesquisa acaba por escapar do cotidiano de tais estabelecimentos. Algumas vezes, o mesmo adentra via reportagens na mídia sobre as pesquisas, via denúncia sobre irregularidades em pesquisas.

As escolhas que se dão no campo na lida com a pesquisa cotidiana não entram nas portas dos CEP, a não ser em relatórios. Porém, as escolhas sobre a forma como o pesquisador se relaciona com os participantes (antes, durante e após a pesquisa), a forma como entra em uma comunidade, a escolha do que será divulgado ou não na pesquisa, a forma de interpretação teórica e mesmo a escolha teórica não são elementos da apreciação ética via protocolos. Neste sentido, a prática da pesquisa pelos membros de CEP é relevante, bem como o diálogo com pesquisadores, participação em congressos e formações. 
Esta questão também pode ser vista quando analisamos a gradação de riscos em uma pesquisa. Inicialmente, o pesquisador pode levantar uma série de potenciais riscos e benefícios e dar subsídios para a avaliação ética entre riscos e benefícios. Porém, é a partir da entrada no campo que teremos uma clareza maior dos efeitos da pesquisa, tanto sobre o pesquisador tanto quanto sobre o participante (seja ele uma pessoa ou uma comunidade). Sendo assim, pelo simples preenchimento da Plataforma Brasil, em quesitos como número de participantes, critérios de inclusão e de exclusão da amostra, não garantem a efetiva realização da pesquisa.

\section{CONCLUSÕES}

A regulamentação externa no fazer do pesquisador foi o tema mais específico neste trabalho, porém na reflexão final torna-se relevante apontar que a ética é parte constante na formação do pesquisador e em sua atuação. As regulamentações aqui discutidas tiveram como ponto de partida a tensão entre compreensões diferenciadas de pesquisa, de seu compromisso social e desejo de inflexão sobre a vida da comunidade. Este embate excede o texto legal e se distribui pelo cotidiano do pesquisador.

Para além de trabalhos burocráticos e, em alguns casos, entraves nas pesquisas, o cotidiano do sistema CEP/CONEP deve primar por sua função educativa no sentido de apontar que a ética não se efetiva apenas regulada ou regulamentada. E esta não é a parte mais relevante. Neste momento histórico, a avaliação ética parece mais constante no cotidiano dos pesquisadores, sendo este um ganho com a efetivação das resoluções éticas em pesquisa, apesar do grande campo de discussões que existe.

A Resolução 510/16 traz contribuições interessantes, mas sua efetivação depende outra resolução (sobre gradação de riscos) e da implementação de novas funcionalidades na Plataforma Brasil. Apesar de a mesma já estar presente no cotidiano dos CEP não se pode falar na efetiva avaliação ética levando-se em conta seus pressupostos. Na disputa e discussão, a resolução consta como marco em que o campo das Ciências Humanas e Sociais se colocam no campo da regulamentação ética, mas ainda como complementar e subordinada ao Ministério da Saúde. Isso já mostra que o caminho para uma regulamentação ainda é longo. Isto é, caso a decisão seja pela regulamentação.

\section{REFERÊNCIAS}

ABREU, Ricardo Nascimento. Aspectos legais envolvidos na coleta de dados linguísticos, p.7-18. In Raquel Meister Ko. Freitag (Organizadora). Metodologia de Coleta e Manipulação de Dados em Sociolinguística, São Paulo: Editora Edgard Blücher, 2014. http://dx.doi.org/10.5151/BlucherOAMCMDS-1cap 
AMARAL FILHO, Fausto dos Santos. Ética e pesquisa nas Ciências Humanas e Sociais: um caso a ser pensado. Práxis Educativa, Ponta Grossa, v. 12, n. 1, p. 257-266, jan./abr. 2017 Disponível em: <http://www.revistas2.uepg.br/index.php/praxiseducativa>.

BRASIL. Resolução $n^{0}$ 466, de 12 de dezembro de 2012, do Conselho Nacional de Saúde, do Ministério da Saúde. Diário Oficial da União 2012; 12 dez.

BRASIL. Resolução $n^{0}$ 510, de 7 de abril de 2016, do Conselho Nacional de Saúde, do Ministério da Saúde. Diário Oficial da União 2016; 7 abr.

DINIZ, Debora. Ela, Zefinha - o nome do abandono. Ciênc. saúde coletiva, Rio de Janeiro , v. 20, n. 9, p. 2667-2674, Sept. $2015 \quad$ Available from <http://www.scielo.br/scielo.php?script=sci_arttext\&pid=S1413-81232015000902667\&lng=en\&nrm=iso>. access on 10 May 2017. http://dx.doi.org/10.1590/1413-81232015209.02832015.

DINIZ, Debora; BRITO, Luciana. "Eu não sou presa de juízo, não": Zefinha, a louca perigosa mais antiga do Brasil. História, Ciências, Saúde - Manguinhos, Rio de Janeiro, v.23, n.1, jan.-mar. 2016, p.113-129.

DINIZ, Débora; GUILHEM, Dirce. 0 que é bioética. São Paulo: Brasiliense, 2008.

FELÍCIO, Jônia Lacerda; PESSINI, Leo. Bioética da Proteção: vulnerabilidade e autonomia dos pacientes com transtornos mentais. Revista Bioética 200917 (2): 203 - 220.

FRANCISCO, Deise Juliana. Criando laços via recursos informatizados. Tese de Doutorado. Programa de Pós Graduação em Informática na Educação, 2008.

FREITAG, Raquel Meister. Aspectos éticos na pesquisa sociolinguística, s/p. Disponível em: <https:/www.researchgate.net/profile/Raquel Freitag/publication/309159946_Aspectos eticos na_pes quisa sociolinguistica/links/5801f0c908ae1c5148cefab4/Aspectos-eticos-na-pesquisasociolinguistica.pdf $>$, Acessado em: maio de 2017.

JÁCOME, Marília de Queiroz Dias; ARAUJO, Tereza Cristina Cavalcanti Ferreira de; GARRAFA, Volnei. Comitês de ética em pesquisa no Brasil: estudo com coordenadores. Rev. bioét. (Impr.). 2017; 25 (1): 61-71.

OLIVEIRA, Luis Roberto Cardoso de. Pesquisa em versus pesquisa com seres humanos. In: VÍcTORA, Ceres. et al. (Orgs.). Antropologia e ética: 0 debate atual no Brasil. Niterói: EdUFF, 2004. p. 33-44.

PEIXOTO, Adriano de Lemos Alves. Regulação e controle ético de pesquisa em Psicologia Organizacional e do Trabalho. Revista Psicologia: Organizações e Trabalho, 16(4), 2016, 324-332.

SILVA, Érica Quinaglia; PEREIRA, Éverton Luís. Ética em Pesquisa: os desafios das pesquisas em ciências humanas e sociais para 0 atual sistema de revisão ética. Revista ANTHROPOLÓGICAS, ano 20, 27(2):120-147, 2016. 